\section{Identification of Cen X-3}

X-RAY observations of the pulsating X-ray source Cen X-3 indicate $^{1}$ that it is a component of an eclipsing binary with a circular orbit of radius $0.08 \mathrm{AU}$. The position and period for Cen X-3 and for its suggested optical counterpart, LR Cen, are given in Table 1 . There is a slight discrepancy in the agreement of the positions and periods. Observations are under way to redetermine the optical period.

Table 1 Position and Period of Cen X-3 and LR Cen

\begin{tabular}{lccc}
\hline & $\alpha(1950)$ & $\delta(1950)$ & Period \\
Cen X-3 (from ref. 2) & $11 \mathrm{~h} 19.0 \pm 0.4 \mathrm{~min}-60^{\circ} 19.2^{\prime} \pm 3^{\prime}$ & 2.087 days \\
LR Cen (from ref. 2) & $11 \mathrm{~h} 21.6 \mathrm{~min}$ & $-60^{\circ} 33.7^{\prime}$ & 2.096 days
\end{tabular}

Photometry of the variable star LR Cen with the 40-inch reflector at the Siding Spring Observatory is shown in Fig. 1. The light curve of LR Cen is typical of an eclipsing binary of the Algol type; the equal spacing of the primary and secondary minima indicates that the orbit is circular and the lack of any constant phase indicates that the eclipse is partial. The time of mid-eclipse of the X-ray source, as calculated from the $\mathrm{X}$-ray data, is also shown in Fig. 1 . It seems that the eclipse of the X-ray source corresponds to the eclipse of the fainter star. Note that a period of 2.090 days, a value midway between the two values given in Table 1, would make the predicted time of the X-ray source eclipse coincide with time of the secondary minimum of LR Cen. Consideration of the colour changes during primary eclipse, along with the shape of the light curve, leads me to the conclusion that the X-ray source is the redder star of the pair, and that it has a low surface brightness with considerable limb darkening. The brighter star is blue with more nearly constant surface brightness.

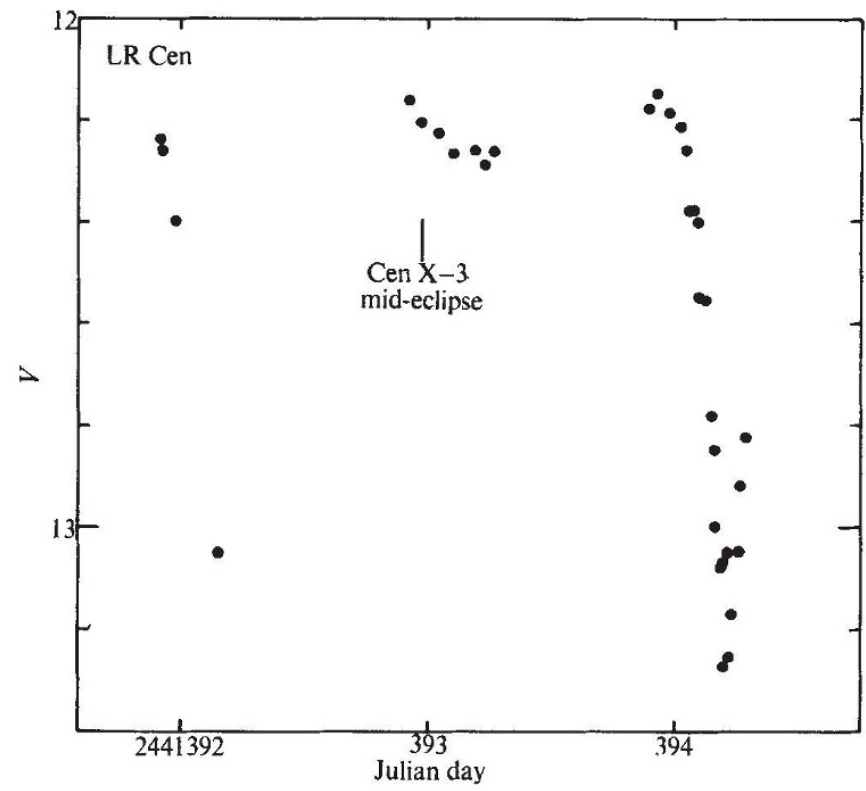

Fig. 1 Light curve of LR Cen.

A search for light variations with a period of $4.84 \mathrm{~s}$, the period of the X-ray pulses, was made during the primary eclipse when the X-ray source was in front of the brighter star. The results of successive $2 \mathrm{~s}$ integrations are shown in Fig. 2. The error bars shown include systematic effects that influence the determination of the zero point as well as random errors from photon statistics which form only $1 / 3$ of the total error shown. Light variations with the period of the X-ray pulses may be present with an amplitude of $2 \%$, but because

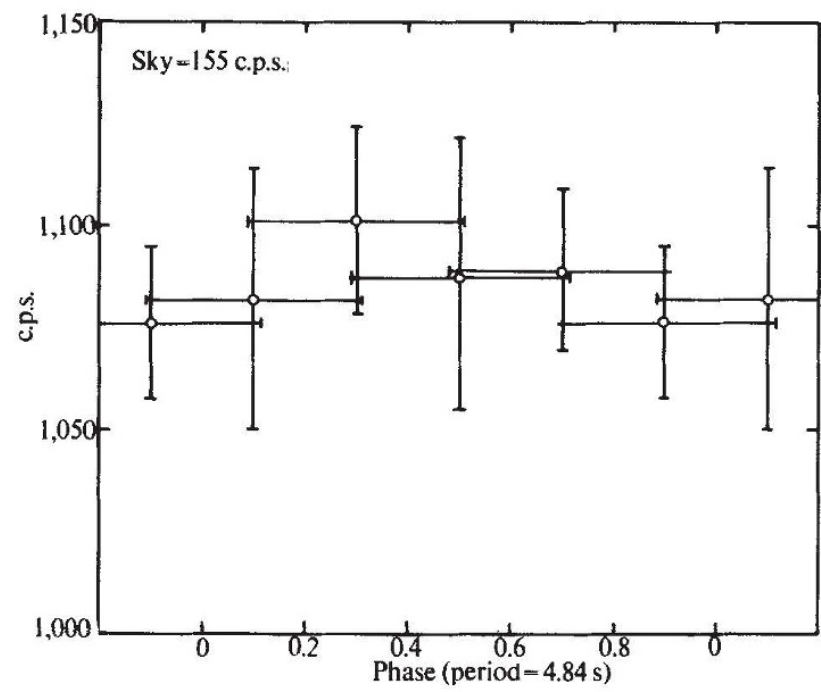

Fig. 2 Light variation of LR Cen with the frequency of the X-ray pulses. Random errors are $1 / 3$ of the total errors shown.

of the large errors in the data, this will require further confirmation before it can be regarded as established. The data set an upper limit of $10 \%$ to the amplitude of light variation with a $4.84 \mathrm{~s}$ period.

My attention was drawn to LR Cen as a candidate for optical counterpart of Cen X-3 by Dr J. Kristian.

Bruce A. Peterson

Mount Stromlo and Siding Spring Observatories,

Research School of Physical Sciences,

The Australian National University

Received March 28, 1972.

${ }^{1}$ Schreier, E., Levinson, R., Gursky, H., Kellogg, E., Tananbaum, H., and Giacconi, R., Astrophys. J. Lett., 172, L79 (1972).

2 Uitterdijk, F., Bull. Astron. Insts. Netherlands, 6, 295 (1932).

\section{Published Analyses of Igneous Rocks}

THE most comprehensive published collection of analyses of igneous rocks ${ }^{1}$ contains more than 7,600 entries considered "superior" by the author. One of us (R. W. Le M.) has a comparable file of 16,050 published analyses, and F. C. has a file of 10,494 published analyses of Cainozoic volcanic rocks alone. Comparison of our files, referred to below as the $\mathrm{C}$ and $\mathbf{L}$ files, provides some basis for estimating how much information of this type has now been published.

The $\mathrm{C}$ file is restricted to analyses of Cainozoic volcanic and related hypabyssal rocks and includes only what petrologists usually consider "complete" analyses, that is those in which the analyst reports values for $\mathrm{SiO}_{2}, \mathrm{Al}_{2} \mathrm{O}_{3}, \mathrm{Fe}_{2} \mathrm{O}_{3}, \mathrm{FeO}, \mathrm{MgO}$, $\mathrm{CaO}, \mathrm{Na}_{2} \mathrm{O}, \mathrm{K}_{2} \mathrm{O}, \mathrm{MnO}, \mathrm{TiO}_{2}, \mathrm{P}_{2} \mathrm{O}_{5}$ and $\mathrm{H}_{2} \mathrm{O}$-recorded in the conventional two-decimal fashion. The $\mathrm{L}$ file contains analyses of igneous rocks of all kinds and ages, and although most of the analyses in it satisfy criteria set up for the $\mathrm{C}$ file, neither "completeness" nor citation to hundredths of a per cent is a condition for inclusion. If each file were based on an exhaustive literature search, file $\mathrm{C}$ would be a subset of file L. If the actual literature searches were independent, the predicted number of published analyses of volcanic and associated hypabyssal rocks to be found in an exhaustive literature search would be $\hat{N}_{\mathrm{V}}=N_{\mathrm{C}} N_{\mathrm{L}} / N_{\mathrm{B}}$, where $N_{\mathrm{C}}$ is the number of analyses in file $\mathrm{C}, N_{\mathrm{L}}$ the number of analyses of volcanic and associated hypabyssal rocks in file $\mathrm{L}$, and $N_{\mathrm{B}}$ the number of analyses common to both files.

For some of the more common volcanic rocks $N_{\mathrm{C}}, N_{\mathrm{L}}$ and $N_{\mathrm{B}}$ have the values shown in Table 1 . Since there is no 